Acta Poetica $32 \cdot 2$

JULIO-DICIEMBRE

$2011(233-254)$

\title{
Unos versos de una carta de amores del siglo XVI en unas probationes calami
}

\author{
Cleofé Tato
}

En este estudio analizo una carta de amores en verso de Diego de la Llana, autor del siglo XVI de quien apenas conservamos tres composiciones. Presto especial atención a la prueba de pluma que figura en un códice quinientista que nos ha transmitido la primera estrofa y el arranque de la segunda del poema, pues esta probatio calami sugiere que la pieza debió alcanzar mayor difusión de lo que el exiguo número de testimonios conservados nos permitía suponer.

Palabras Claves: Diego de la Llana, probatio calami, carta de amores, poesía del siglo XVI.

This paper analyzes a love-letter written in verse by Diego de la Llana, a 16 th Century author of whom only three compositions have survived. Special attention is paid to a probatio calami in a 16th Century codex, in which we were introduced to the first stanza and the beginning of the second one. This probatio calami suggests that this literary piece must have been more wide-spread than one would presume from the few preserved works.

KEYwORDS: Diego de la Llana, probatio calami, love-letter in verse, 16th Century poetry.

Fecha de recepción: 6 de marzo de 2010

Fecha de aceptación: 14 de junio de 2010 

Cleofé Tato

Universidad de A Coruña

\section{Unos versos de una carta de amores del siglo XVI en unas probationes calami ${ }^{1}$}

La importancia que para el estudio de los textos literarios tienen las anotaciones introducidas con posterioridad por diversas manos en manuscritos e impresos está fuera de duda, hasta el punto de que, tengan o no que ver con el contenido de la obra principal a la que acompañan, deben ser siempre objeto de atención para el investigador. Es verdad que a veces no aportan más que un garabato sin sentido, un nombre que no llegamos a individualizar o un apunte de cuentas; aun así, debemos examinarlas con detenimiento. Otras veces, por el contrario, nos permiten descubrir un texto literario del que no disponíamos o una nueva versión de alguna pieza que conoce otros testimonios. En tales ocasiones su valor se incrementa notablemente, de manera que lejos de verlas como un deterioro del códice o el impreso, podemos considerarlas una preciosa e irregular fuente literaria. $^{2}$

${ }^{1}$ Este trabajo se inscribe en el marco de los proyectos de investigación FFI201017427, financiado por el Ministerio de Ciencia e Innovación, e INCITEO9PXIB10424PR, subvencionado por la Xunta de Galicia.

${ }^{2}$ Recojo alguna bibliografía sobre pruebas de pluma en Tato, "Una nueva y fragmentaria versión del romance", 280. 
En estas páginas pretendo ocuparme de algunas notas añadidas a un códice de principios del siglo XVI, conservado en la Biblioteca Nacional de Madrid (ms. 3338), que nos ha transmitido varias obras de carácter científico. ${ }^{3} \mathrm{Da}$ la sensación de que cuando el vuelto del último folio estaba totalmente en blanco, una mano posterior a las que intervinieron en la copia del códice (no muy alejada del momento en que se confecciona este), con letra menos cuidada y más cursiva, hace una prueba de pluma y copia en el centro del folio los dos primeros dieciseisílabos de un romance viejo cuyo íncipit reza "Muerto yaze Durandarte". ${ }_{4}$ Más tarde, otra mano distinta aprovecha el espacio en blanco que queda en la parte superior del folio y transcribe, como si fuese prosa, un breve fragmento de una composición poética cuyo arranque reza "Muy deseada señora" (y parece que la causa de que no prosiga con la segunda estrofa es que se tropieza con los versos, antes copiados, de "Muerto yaze Durandarte"). Todavía más arriba se repiten los tres primeros versos de la composición con una letra más cuidada y respetando la pausa versal $;{ }^{5}$ finalmente, una última mano ocupa la parte inferior del folio, que había quedado en blanco, y nos ofrece el testimonio de un suceso que fecha en $1565 .{ }^{6}$

Por lo que concierne a los versos que preceden al muy difundido romance de Durandarte, se trata del comienzo de una canción quinientista mucho menos conocida. Como he indicado, se escribe dos veces: en la parte superior del folio se trasladan

${ }^{3}$ Un breve análisis sobre su materialidad puede verse en Pérez Pascual, La "Suma de la flor de cirugía", 48-51.

${ }^{4}$ En Tato, "Una nueva y fragmentaria versión del romance", he tratado acerca de este ensayo de escritura.

${ }^{5}$ Puede ser una tercera mano que, algo después, se distrae recopiando lo que lee algo más abajo, pero introduciendo la pausa versal. Desde luego, si es obra de la misma mano, la tarea se hace en un momento diferente y se cuida algo más la escritura.

${ }^{6}$ En este último caso, más que ensayar la pluma, el que escribe parece ensayar la redacción del texto. 
al papel los tres primeros octosílabos respetando la pausa versal, aunque luego se tachan; más abajo, copiada como prosa, figura la primera estrofa y el arranque de la segunda: ${ }^{7}$

Muy deseada señora: / de mí, que soy su criado, / como mi mal enpeora, / la quise hacer sabidora / por lo que verá trovado. / Por ende puede entender, / señora, quánto al presente / -sy puédelo bien crer- / que quisiera yo más ser / mensagero que escribiente // Siquiera para

Aun cuando no se consigna nombre de autor, el texto es debido a un poeta del siglo XvI, Diego de la Llana, de cuya breve producción da cuenta Antonio Rodríguez-Moñino en su Diccionario de pliegos sueltos. Allí recoge uno cuya portada presenta una orla, que califica de "muy bella", y el título Disparates muy graciosos. Ahora nueuamente conpuestos, por Diego de la llana d la villa de Almenar. Y otras en carta a vna señora $q$ el seruia, suplicãdo le le tega por suyo. Y otras a vna borracha. ${ }^{8}$ Este impreso, uno de los pliegos góticos custodiados en la Biblioteca Nacional, es el testimonio principal de la poesía de nuestro hombre; 9 tal como se indica en la portada, contiene tres poemas: "Yo queriendo caminar / de Burgos para Medina", "Muy desseada señora: / de mí, que soy su criado" y "Poned luto taberneros / por la triste de Marigarcía". ${ }^{10}$

${ }^{7}$ Me limito a desarrollar las abreviaturas (que marco en cursiva), y a introducir puntuación y acentos; más adelante enfrento esta versión a la contenida en un pliego suelto.

${ }^{8}$ Véase Rodríguez Moñino, Nuevo diccionario de pliegos sueltos poéticos (siglo $X V I)$, núm. 320.

${ }^{9}$ El pliego se incorpora en dos ediciones facsímiles: en la de Castañeda y Huarte, Nueva colección, núm. XIII, y en Pliegos poéticos góticos de la Biblioteca Nacional, III, núm. 97. En mis citas de los textos me limito a introducir acentuación y puntuación, a segmentar las palabras según el uso moderno (introduciendo, cuando es preciso, el apóstrofo), así como a regularizar mínimamente la ortografía (en especial el uso de $v / u$, y el de $y / i / j$ para vocales y consonantes).

${ }^{10}$ Sobre la llegada del volumen que contenía este y otros pliegos góticos a la Biblioteca Nacional y su procedencia, véase Moll, "Tres volúmenes de pliegos suel- 
El impreso era conocido con anterioridad. Agustín Durán había informado sobre él: un pliego sin indicación de lugar y año, en cuarto, de cuatro hojas, escrito con letra gótica a dos columnas (Durán, “Catálogo por orden alfabético", LXXIII). Por otra parte, en el Ensayo de Bartolomé José Gallardo se recoge alguna de las piezas allí contenidas y breves fragmentos de las otras dos. ${ }^{11}$ Asimismo, se formulan algunas conjeturas acerca de Diego de la Llana y del posible impresor de sus textos: sobre el primero, seguramente a partir de ciertas alusiones en "Yo queriendo caminar" (por ejemplo, la referencia al Perú y a Flandes: "un castillo en un alano / que parte para el Perú / [...] y los baños de Ledesma / se passavan para Flandres"), ${ }^{12}$ se concluye que era escritor del siglo XVI y que podría proceder de Extremadura (se alude en esa misma pieza a alguna zona pacense: "y vi que recibió daño / toda la Serena d'esto"), de donde, a juicio de Gallardo, proviene algún idiotismo (menciona en concreto en un repiquete, 'instante': “y vi que en un repiquete / se juntaron las hormigas"). ${ }^{13}$ Cierra su reflexión, no

tos". Ninguno de los íncipits citados se recoge en Labrador Herraiz y DiFranco, Tabla de los principios de la poesía española.

${ }^{11}$ Se edita la tercera de las piezas y los fragmentos del disparate y de nuestra carta de amores; véase Gallardo, Ensayo de una biblioteca, III, 575-578, núm. 2860.

${ }^{12}$ La conquista del Perú fue larga y pasó por diversas fases, pues si bien comenzó en los años veintes del siglo XVI, los problemas y enfrentamientos con los indígenas perduraron largo tiempo; muerto Pizarro en 1541, todavía continuó la resistencia indígena hasta que falleció el príncipe Manco Cápac II (1544). Por lo que concierne a Flandes, el ducado se incorpora a la Corona tras la muerte de Fernando el Católico, cuando Carlos I accede al trono (1516). También se mencionan los baños de Ledesma, cuyas propiedades curativas parecen ser conocidas ya en tiempos de los Reyes Católicos (véase Rosa y Mosso, "Historia de las aguas", 121).

${ }^{13}$ Aunque Gallardo era oriundo de Extremadura, tras rastrear dialectalmente la voz repiquete, que se documenta también en otros puntos, no creo que pueda aducirse su condición de idiotismo extremeño en este caso; Viudas Camarasa registra la palabra en Badajoz, pero con la única acepción de 'entierro de niño', que no parece ser la de nuestro texto (Diccionario extremeño, s.v.). Por otra parte, interesa notar que no figura ningún poeta de apellido Llana entre los extremeños que se incluyen en Rodríguez-Moñino, Los poetas extremeños, ni tampoco en el Catálogo bibliográfico de escritores extremeños preparado por Cañas Murillo y Teijeiro Fuentes. 
obstante, con la interrogación: "Acaso, si no sería serrano burgalés; y estas piezas están impresas en Burgos por F. de Junta?" (Gallardo, Ensayo de una biblioteca, III, 577, núm. 2860).

También Vicente Castañeda y Amalio Huarte, al preparar la edición facsímil de este y otros pliegos de la Nacional, dan al que contiene la pieza "Muy desseada señora" el número $13 \mathrm{y}$ hacen algunas consideraciones de interés: aun cuando en él no consta nombre de impresor ni fecha, por las coincidencias que, a su juicio, ofrece con otro pliego suelto, apuntan la idea de que habría sido impreso por Juan de Junta en Burgos hacia 1535. ${ }^{14}$ No obstante, recuperan también la sugerencia de Gallardo de ligarlo a Felipe de Junta, descendiente del anterior, recordando además que hay otro pliego de Felipe que reproduce la pieza superior de la orla de la portada. ${ }^{15}$

El abanico temporal que nos abren los dos Junta es bastante amplio, pues mientras Juan, el padre, muere en 1558 y parece estar activo como impresor desde 1527, su hijo Felipe, que continúa con la actividad editorial familiar, fallece a fines de 1596 o a principios de $1597 .{ }^{16}$ Las perspicaces observaciones

${ }^{14}$ Véase Castañeda y Huarte, Nueva colección, XIV; también Palau y Dulcet lo vincula a Juan de Junta y lo sitúa hacia 1535 (Manual del librero, VIII, 4b), al igual que Di Stefano ("Aggiunte e postille"). Fernández Valladares desecha definitivamente la comparación entre los pliegos establecida por Castañeda y Huarte, "pues las tipografías son diferentes en ambas ediciones", y rechaza, asimismo, la fecha de 1535 (La imprenta en Burgos, II, 983-984; véase también infra n. 16).

${ }^{15}$ Castañeda y Huarte, Nueva colección, XIV-XV y VIII. Fernández Valladares considera "más pertinente" que la anterior (vid. supra n. 13) esta indicación de Castañeda y Huarte a propósito del adorno de la orla, empleada por Felipe de Junta — por más que advierte de que el ejemplo concreto aducido para ilustrar la afirmación está equivocado (Fernández Valladares, La imprenta en Burgos, II, 983b).

${ }^{16}$ De ascendencia italiana, los Junta (el apellido ofrece diversas variantes) comerciaban inicialmente en Florencia con lanas, aunque a fines del siglo XV pasaron a ocuparse de los libros. Extienden el nuevo negocio por varias ciudades de la geografía europea; a España llegará más de una rama de la familia: la que aquí importa es la que tiene como miembro más antiguo a Juan de Junta, quien, tras pasar por Salamanca, comienza a imprimir en Burgos (hay constancia de su actividad desde 1527), donde se casa hacia 1526 con la viuda de Alfonso de Melgar, Isabel de Basilea (heredera del taller del célebre Fadrique de Basilea); a principios de 1532 Juan 
de Mercedes Fernández Valladares dejan, no obstante, resuelto el problema: pese a la falta de indicaciones tipográficas del pliego, la impresión corre a cargo de los Herederos de Juan de Junta y puede fecharse en torno a $1558 .{ }^{17}$ Este año podría, por tanto, servir como referencia temporal a la hora de estudiar la obra de Diego de la Llana (sería el término ante quem).

Ahora bien, muy poco más sabemos acerca de este poeta, que sobre todo es mencionado por la crítica merced a su contribución al género del disparate. ${ }^{18}$ Según colegimos del capítulo XLIX de la segunda parte del Quijote, el nombre no debió de ser infrecuente en el Siglo de Oro. Durante la ronda nocturna en la Ínsula Barataria, Sancho tropieza con una joven disfrazada de varón que resulta ser hija de Diego de la Llana, conocido del mayordomo que acompaña a Sancho y presentado por aquel como "un hidalgo principal y rico" (Don Quijote, II, 1031). ${ }^{19}$

de Junta abandona Burgos, ciudad a la que no regresará, y vuelve a Salamanca para continuar imprimiendo allí obras a su nombre hasta 1552 (por entonces, ya ausente de la Península, la imprenta salmantina vive algunos problemas y emerge la figura de Matías Gast, que se convertirá en 1554 en yerno de Juan de Junta). Y es que de la unión de Juan e Isabel habían nacido dos hijos: Felipe, venido al mundo en Burgos hacia 1530, y Lucrecia, quien ve la luz en Salamanca en 1537. Ambos continuaron, tras la muerte del padre en 1558, con la tradición familiar; imprimen bajo el pie de imprenta "Herederos de Juan de Junta" en Salamanca y en Burgos hasta 1560. Felipe será el que mantenga luego la actividad editorial, heredera del fundador Fadrique de Basilea, en la ciudad del Arlanzón; allí empieza a imprimir en 1562 y lo hace hasta 1596 (pero desde 1593 por lo menos trabaja con su yerno Juan Bautista Varesio). Véase un detallado estudio de la actividad de Juan, de sus herederos y de Felipe de Junta, en Fernández Valladares, La imprenta en Burgos, I, 154-187; un resumen más breve en Delgado Casado, Diccionario de impresores, I, s.v. Junta (familia), Junta, Juan y Junta, Felipe y en Cuesta Gutiérrez, La imprenta en Salamanca, 26-28.

${ }^{17} \mathrm{Su}$ datación está sólidamente fundamentada: "La pieza xil. superior que forma el entablamento muestra el ángulo inferior derecho desgastado exactamente en el mismo estado en que aparece en dos ediciones de este año 1558" (La imprenta en Burgos, II, 983b).

${ }^{18}$ Véase sobre este género Gauthier [Foulché-Delbosch], "De quelques jeux d'esprit", 419-424; Periñán, "Poeta ludens”, 13-78 y 119-162.

${ }^{19}$ En primera instancia, la joven declara ser hija de Pedro Pérez Mazorca; el mayordomo la desmiente, pues dice conocer a Pedro Pérez, que no tiene descendencia. Es entonces cuando la muchacha rectifica y dice ser hija de Diego de la Llana. 
Lo cierto es que, como se precisa en la edición de Francisco Rico,

Diego es siempre nombre de nobles en el teatro de Lope de Vega, según Morley y Tyler; la Llana remeda, si no pertenece al grupo, la estructura de muchos grandes linajes aragoneses: Lanuza, Lanaja, La Cadena, Lastanosa, etc. Recuérdese que Murcia de la Llana es apellido del corrector de erratas de las dos partes del $Q$ ("Notas complementarias a Don Quijote", 596, n. $1031-50) .{ }^{20}$

Ciertamente, aun cuando no se registra el apellido en las $B i$ bliotecas antigua y nueva de escritores aragoneses de Latassa, no puede excluirse esta posibilidad. No obstante, por lo que en concreto toca a la localización geográfica de nuestro hombre, el título del pliego permite entrar en mayores precisiones: allí se aplica a Diego de la Llana la frase preposicional de la villa de Almenar, topónimo que podría, en principio, llevarnos a Soria o a Lérida y que indicaría el lugar en donde aquel reside o, más probablemente, el lugar de donde procede. A esto cabría añadir el hecho de que en su juego de disparates, entre los muchos lugares que cita por dos veces menciona Medina, quizás la localidad burgalesa de ese nombre (Medina de Pomar), no muy lejana de Almenar de Soria ${ }^{21}$ asimismo, es posible todavía reforzar la

${ }^{20} \mathrm{El}$ apellido de la Llana se repite, asimismo, entre los autores incluidos por Pedro Espinosa en un florilegio poético de principios del XVII: se trata del licenciado Juan de la Llana, natural de Antequera; véase Rodríguez-Moñino, Manual bibliográfico, 104-118. Otros Llana se localizan en Palau y Dulcet, Manual del librero, VIII, 4-5.

${ }^{21}$ En un caso para introducir una dislocación geográfica, algo frecuente en el género del disparate ("Yo queriendo caminar / de Burgos para Medina, / quiso la gracia divina / que amanescí en Gibraltar"), en otro para hacer referencia a la feria de Medina ("un pendón con cien mastines / para feria de Medina"); con todo, y dada la explícita referencia a la feria, nada impide relacionar esta última localidad con Medina del Campo, próxima a Valladolid y célebre por su feria. Sobre el juego de los disparates y las referencias espacio-temporales, véase Periñán, "Poeta ludens", 50. También en otra de sus obras, "Poned luto taberneros", se localizan topónimos que nos remiten a la geografía castellana. 
idea admitiendo que tras la impresión del pliego suelto estarían los Junta, hacia quienes podría apuntar la belleza de la orla. ${ }^{22}$

Es difícil, pues, mantener de forma incuestionable la sugerencia de Gallardo sobre el origen extremeño de Diego de la Llana; ${ }^{23}$ más bien hemos de localizarlo, como también este investigador apunta, en Burgos, o con mayores garantías, simplemente en Castilla. De hecho, es muy posible que el códice que contiene esta prueba de escritura hubiese pertenecido a alguien de tal procedencia y hubiese circulado en esta zona. Así, en otras pruebas de pluma de menor interés que enseguida comentaré, la geografía castellana reaparece como fondo, sin olvidar que un colofón al final del manuscrito nos informa que fue acabado en Toledo. ${ }^{24}$

De esas otras pruebas de escritura me interesa especialmente la final, que debió de añadirse después de las hasta ahora comentadas. Se trata de un testimonio que contiene una breve relación de un suceso que, según se indica, aconteció en 1565; ello nos lleva necesariamente a una fecha posterior a ese año para este apunte que por momentos es difícilmente legible: ${ }^{25}$

${ }^{22}$ Los trabajos de Juan de Junta, tanto los impresos en Salamanca como en Burgos, "tienen un carácter francamente renacentista y la marca italiana se acusa en las orlas, medallones, grutescos y otros adornos que abundan en sus libros, lo mismo que en los escudos tipográficos que emplea, todo ello hecho con una finura y gracia insuperables" (Cuesta Gutiérrez, La imprenta en Salamanca, 27-28). No se puede olvidar, sin embargo, que es posible que esa tradición ornamental de los Junta remonte al fundador, Felipe de Basilea, tal como parece evidenciar el inventario de la librería de Juan de Junta, realizado en 1557 (véase Fernández Valladares, La imprenta en Burgos, I, 130, esp. n. 20). Lo cierto es que, aun cuando la fecha del pliego nos lleva a 1558, muerto ya Juan de Junta, la orla empleada por sus herederos es elaborada: "Dentro de una orla arquitectónica de cuatro piezas xil. mostrando, el entablamento, dos aves que, enlazadas por el cuello a sendos lagartos, portan en el pico una corona de laurel con un aguilucho; en las bandas laterales columnas abalaustradas y en la basa, dos dragones portando un escudete en blanco, tres tacos xil. de figurillas: casas, dama galán y debajo el título" (II, 983b).

${ }^{23}$ El propio Gallardo, por otra parte, parece ponerlo en duda.

${ }^{24}$ Véase Pérez Pascual, La "Suma de la flor de cirugía", 50.

${ }^{25} \mathrm{Al}$ final el texto se corta porque el folio tiene una rotura en la parte inferior izquierda, aunque quedan restos de lo que parece la rúbrica de una firma. 
bino la crecida de Huécar sábado, a las diez de la noche, y pasó por la Puerta de Nuestra Señora de la Conçebçión una bara en alto y no entró dentro, que fue a cinco de mayo, anno de mil e quinientos sesenta y çinco años y, porque es berdad, como testigo de vista, lo firmo de mi non[bre $]^{26}$

En mi opinión, es probable que se haga referencia aquí a una crecida del río Huécar, que junto al Júcar conforma la red hidrográfica conquense. ${ }^{27} \mathrm{Y}$ aun cuando es cierto que este río no es muy caudaloso, parece haber anegado las tierras colindantes en más de una ocasión. ${ }^{28}$ El testimonio recogido en el

\footnotetext{
${ }^{26} \mathrm{Me}$ limito a regularizar el uso de $i / j$. El paréntesis final es reconstrucción, porque ahí se corta la frase.

27 "Júcar y Güécar, y Cuenca en medio", reza un decir recogido por Covarrubias (véase Covarrubias Horozco, s.v. Júcar y Güécar). El lexicógrafo, natural de Cuenca, frente a lo que hace al explicar otros topónimos, en los que a veces ofrece información errónea o datos inexactos, se demora al llegar a la voz Cuenca en presentar una descripción precisa y plagada de detalles que seguramente conocía de su propia experiencia (véase González Aranda, "El léxico toponímico"). Pero también Juan Pablo Mártir Rizo, al hacer la historia de la ciudad y tras referirse al río Júcar (Historia de la muy noble y leal ciudad, 5-7), presta atención al Huécar, del que dice: "No es de menos importãcia el rio Huecar para Cuẽca, pues aunque no de tanto caudal, resulta de sus pocas aguas mucho prouecho, porque viene regando vna legua de huertas, de donde procede toda la prouisión de hortalizas, y frutas, y siruen tãbien para el trato de los paños, pues no se sabe, q en España sean mas finas las colores de la lana, que las que aquí se tiñẽ, que es vna de las cosas q hã hecho a esta Ciudad tan nombrada. Y no le deue poco Cuẽca a este rio, por lo q auemos dicho, como porque en los tiẽpos passados la hizo tan fuerte, y inexpugnable por la parte de lo llano, como lo es por la de los peñascos, y riscos, pues derramando sus aguas por aquellos campos hazia tan grandes pantanos, que era imposible entralle a pie, ni a cauallo, quãdo las alteraciones destos Reynos en tiempo del Rey don Iuan el Segundo, como luego diremos" (7-8; la cursiva es mía). Sobre el escaso caudal, a lo indicado por Mártir Rizo puede añadirse el comentario de Covarrubias: "De dos ríos que pasan por Cuenca, y toman la ciudad en medio, el uno es Júcar, y el otro Güécar, río pequeño, que riega toda la hoz donde hay muchas güertas, una legua desde Palomera a Cuenca. Dicen los arábigos vale tanto como comedimiento, por ser comedido en su corriente y llevar poco agua. En llegando cerca de los muros de Cuenca sirve a los tintoreros de lavar la lana, y entra en Júcar por los tintes, que están poco encima de la puente" (Tesoro de la lengua, s.v. Güécar; la cursiva es mía).

${ }^{28}$ Como recuerda Mártir Rizo, el Huécar "derramando sus aguas" servía también de contención en tiempos de Juan II (véase supra n. 26); en fechas más recientes se pro-
} 
ms. 3338 de la Biblioteca Nacional daría, pues, cuenta de un hecho excepcional: un río habitualmente poco caudaloso como el Huécar se desborda y sube una vara de alto en la puerta del Convento de la Concepción. ${ }^{29}$

Como argumento para apoyar esta localización del fenómeno en Cuenca puede aducirse que el Huécar, a su paso por esta ciudad, corre junto al Convento de la Concepción, un monumento fundado a fines de 1500 o principios de 1501 por el canónigo de la catedral de Toledo Alvar Pérez de Montemayor; ${ }^{30}$ las obras debieron de llevarse a cabo rápidamente, pues estaba ya edificado en octubre de $1504 .{ }^{31}$ En cuanto al uso de la voz vara con el significado de medida, es una acepción bastante común, seguramente bien conocida para un habitante de la ciudad manchega, sin duda familiarizado con la industria de paños y lanas. ${ }^{32}$ Falta el nombre del testigo que da fe de la crecida del

dujeron otros desbordamientos (véanse El País, 02 de junio de 1979; El Mundo, 14 de agosto del 2010). Y ello sin olvidar que en Cuenca la Calle del Agua recibe este nombre por las inundaciones que en ella se producen cuando el agua del Huécar sale de su cauce.

${ }^{29} \mathrm{Sin}$ embargo, no he encontrado referencia documental del suceso; agradezco a Nieves Pena Sueiro su ayuda en esta infructuosa búsqueda.

${ }^{30}$ Mártir Rizo lo incluye entre los monasterios de la ciudad y sitúa su fundación en 1507 (Historia de la muy noble y leal ciudad, 105). Barrio Moya precisa que, aun cuando Mártir Rizo acierta en el nombre del fundador del convento, se equivoca, en cambio, al ofrecer la fecha de su fundación, algo anterior (“José Martín de Aldehuela", 66).

${ }^{31}$ Levantado sobre el emplazamiento de la antigua ermita de la Santísima Trinidad, se hallaba frente a la desaparecida Puerta de Valencia, abierta en las murallas medievales de Cuenca; la iglesia actual remonta a una remodelación del siglo XVIII, aunque conserva la portada renacentista (Barrio Moya, "José Martín de Aldehuela", 67-68). Mártir Rizo da cuenta del cambio de manos de la antigua ermita de la Trinidad: "El [monasterio] de San Francisco se fundó en tiempo del Rey don Alonso, porque viniendo en su seruicio à esta conquista los Caualleros Templarios se les concedió vna Casa, o Conuento en los burgos de la ciudad. Y como después esta Religion fue extincta por los años de mil y trezientos y treze, se dio su Iglesia, o Cõuento à los Religiosos cõuentuales de san Francisco, y dellos vino à los Obseruantes el año de mil y quinientos. El Monasterio de la santissima Trinidad es de los mas antiguos della" (Historia de la muy noble y leal ciudad, 103).

${ }^{32}$ Además de ser empleada con el valor del término latino VIRGA ('palo largo y delgado'), conoce el sentido de medida ya en el Conde Lucanor (Corominas y Pascual, Diccionario crítico, s.v. vara). La acepción "medida para medir paños, sedas, 
río, pero hemos de suponer que hacia 1565 residía en Cuenca; la geografía deducible de otras pruebas de escritura contenidas en el manuscrito 3338 nos lleva, asimismo, a Castilla, hacia donde señala otro apunte localizado en el folio $116^{\mathrm{v}}$ : allí en el margen de cabeza se anota lo que parece un nombre, tal vez Alonso de Pereçuela, y en el margen de pie, la procedencia, de la villa de Uclés, cercana a Cuenca. ${ }^{33}$

Sea cual sea la fecha de la última de las pruebas de escritura consignada en el último folio del ms. 3338 (siempre posterior a 1565), todo parece indicar que el volumen manuscrito circuló durante el siglo XVI en la zona castellana, en donde en distintos momentos diferentes manos ejercitaron la pluma en los márgenes y en un folio que había quedado en blanco. Muy probablemente la que copia el fragmento de la composición de Diego de la Llana recupera un texto de un autor próximo geográficamente, compuesto antes de 1558 , momento cuando se imprime el pliego, y quizás después de 1530 (veáse supra $\mathrm{n}$. 11).

Es ciertamente muy poco lo que podemos decir de la obra de este escritor; de su exigua producción, la pieza que mayor interés ha suscitado, según he indicado, es el disparate "Yo queriendo caminar", pero tampoco pasó inadvertida la que comienza "Poned luto taberneros", asociable también al disparate aunque con mayor precisión catalogable como testamento poético burlesco, pues precedida de la indicación Otras a una borracha dispone las voluntades de la triste Mari García, fallecida por su afición al vino. ${ }^{34}$ Ambas modalidades, el disparate y el testamento burlesco, hunden sus raíces en la tradición cancioneril.

lienzos y otras cosas que tengan trato o longitud" es documentada por Covarrubias (Tesoro de la lengua, s. v. vara).

${ }^{33}$ Así como la localización geográfica se lee sin dificultad, no ocurre lo mismo con el nombre, que está abreviado. En el margen de pie hay todavía otra prueba seccionada por la cuchilla; hoy se lee "dizen que quienq" (quizás seguía "quienquiera"). Resulta difícil determinar si estamos ante la misma mano que redacta la breve relación del suceso acaecido en 1565 .

${ }^{34}$ Véase Rubio Árquez, "Testamentos poéticos burlescos" (esp., 250); sobre los 
Por lo que toca a la composición copiada en la prueba de pluma que ahora nos ocupa, el texto completo es bastante más extenso: comprende nueve estrofas de diez versos octosilábicos seguidos de un cierre de cuatro $(10 \times 9,4)$ de acuerdo al patrón de rimas $a b a a b c d c c d$; se trata de una copla real integrada por dos semiestrofas simétricas con cuatro rimas (abaab : $c d c c d) .{ }^{35}$ Este tipo de combinación remonta a la poesía cancioneril, en donde "fue destacándose sobre las demás combinaciones hasta hacerse reconocer como representación característica de la copla real y como una de las estrofas más peculiares de la poesía castellana del siglo Xv" (Navarro Tomás, Métrica española, 109). ${ }^{36}$ En el XVI, la copla real fue también frecuentemente cultivada, y en concreto se dio con más abundancia la forma de cuatro rimas que la de tres, por más que parece haber sido más corriente la copla de cuatro rimas con semiestrofas combinadas de distinto modo que el tipo simétrico que presenta "Muy desseada señora". ${ }^{37}$ Atendiendo al contenido, estamos

antecedentes medievales puede consultarse también Chas Aguión, "Los testamentos en la poesía de cancionero".

${ }^{35} \mathrm{El}$ cierre no enlaza las rimas con las de la última estrofa, a la manera en que normalmente sucede en la finida; tampoco cuenta con cinco versos, como sería lo esperable a partir de la copla precedente, integrada por dos semiestrofas de cinco versos.

${ }^{36}$ Sin aducir ningún ejemplo concreto, indica Navarro Tomás que el tipo simétrico $a b a a b$ : $c d c d c$ se inicia en el Cancionero de Baena y es repetido con preferencia por Juan de Mena (Métrica española, 109), quien se sirvió incluso de otras combinaciones de rimas (108). Henry Lang ofrece la referencia de uno de los textos de aquel cancionero, si bien se vale de una de las adiciones incorporadas tardíamente a la compilación preparada por Juan Alfonso de Baena; me refiero a "Rey virtud Rey vençedor" (ID 0161) de Juan de Mena (véase "Las formas estróficas y términos métricos", 493; el número ID corresponde a las convenciones de Dutton, El cancionero del siglo $\mathrm{XV}$ ). Con todo, lo cierto es que este esquema de rimas abaabcdccd se repite en muchos poetas y textos a lo largo del siglo xv (véase Gómez-Bravo, Repertorio métrico de la poesía cancioneril, 395-433, núm. 1681).

${ }^{37}$ Así lo afirma Navarro Tomás, quien señala, no obstante, que se hallan asimismo ejemplos de combinaciones simétricas; por ejemplo, el nuestro ( $a b a a b: c d c c d$ ) lo localiza en la tragedia Filomena y en el paso de La razón y la fama, de Timoneda, así como en la poesía de Boscán sobre la definición de amor (Métrica española, 199). 
ante una composición amorosa que podemos relacionar con las llamadas cartas de amor, cuyas raíces nos llevan hasta la lírica cuatrocentista, en la que la composición de Santillana "Gentil dueña cuyo nombre” (ID 0324) "pasa por ser el ejemplo más antiguo conocido en la lírica cuatrocentista castellana" de carta de amores (Pérez Priego, Poesía lírica, 39, n. 1). ${ }^{38}$ Ello podría tomarse como un indicio de su antigüedad; no obstante y pese a que en el siglo XV contamos con importantes muestras del género, es preciso recordar la indiscutible importancia de la epístola en el Renacimiento. ${ }^{39}$ En este caso, podemos encuadrar el poema de Diego de la Llana en las cartas en octosílabo; la mayoría son cartas de amores. ${ }^{40}$ La rúbrica que antecede al texto explícitamente se vale de la voz carta, anticipando así la modalidad con que nos vamos a encontrar: Carta que embió a una señora que él servía loándola de hermosa, y suplicándole tenga por suyo; no faltan en el cuerpo de la composición marcas del género epistolar, como por ejemplo la salutatio inicial, si bien el elogio y la queja del enamorado, embebidos en la misiva, son los elementos más destacables. ${ }^{41}$

En cuanto al tratamiento de temas y motivos, "Muy desseada señora" puede caracterizarse como un poema engastado en los viejos modos cancioneriles; el yo lírico nos habla de la per-

${ }^{38}$ Podría todavía señalarse como antecedente el salut d'amor provenzal, sin olvidar las Heroidas de Ovidio y aun otras posibles influencias; véase al respecto Le Gentil, La Poésie lyrique espagnole et portugaise, I, 225-227; también Lapesa, "“Cartas' y 'dezires"”.

${ }^{39}$ Véase sobre la epístola, Pontón, Correspondencias: Los orígenes del arte epistolar en España; allí puede encontrarse otra bibliografía. Sobre su desarrollo en el Renacimiento, véase López Bueno, La epístola.

${ }^{40}$ Véase Díez Fernández, "Notas sobre la carta".

${ }^{41} \mathrm{Y}$ es que el anuncio de la primera estrofa sobre la preferencia del yo de ser mensajero más que escribiente permite introducir el elogio desmedido: siendo mensajero, verá el gesto tan singular de su dama....; luego vendrá la queja. En la conclusio se emplea también una fórmula similar a las registradas en muchas cartas: "El que suyo siempre fue / y será mientras biviere, / y el que tiene tanta fe / que por sus amores muere". 
fección de la mujer a la que se dirige, de su crueldad, de la pena que sufre como amante (con alusión incluso a la muerte: "causáis tanta pena en mí / que de aquel punto que os vi / hasta aquí hazéis que muera"), de su lealtad ("sino que soy su captivo / -y en esto no ay dubdar- / siempre me podrá mandar / desde ahora y mientras bivo"). ${ }^{42} \mathrm{Y}$ algo similar ocurre con los recursos empleados, entre los que destaca especialmente la superlatio: la dama es presentada como obra maestra de Dios ("porque el pintor soberano / con el pinzel celestial / traçando su sabia mano / causó, en vos, no ser humano / vuestro gesto angelical"), al tiempo que se incide en el tópico de lo indecible, que limita la capacidad discursiva del poeta ("porque soys tan acabada / y hecha por tal perfeción, / de mil virtudes dotada, / que mi pluma está cansada / buscando comparación"); en este ámbito de la superlatio es preciso resaltar que no falta la hipérbole numérica, una de las más características de la poesía cancioneril ("de mil virtudes dotada", "Cuerpo gracioso gentil, / hecho por primo compás, / muy delicado y subtil, / tanto que en trezientos mil / otro tal no vi jamás"). ${ }^{43}$ Pero también se salpican otros recursos frecuentes entre los poetas cuatrocentistas: la acomodación de algún refrán (“dar lançada a moro muerto") ${ }^{44}$ el juego de los antónimos ("y en lugar de mejorar /

\footnotetext{
${ }^{42}$ Quizás el motivo menos común se localice al final del poema: antes de pedir a la amada que se acuerde "quánto fue de mi servida", el poeta ruega a Dios que a su dama "le dé la vida tan luenga / como dio a Matusalem".

${ }^{43}$ A propósito de la superlatio en la poesía de cancionero véase Casas Rigall, Agudeza y retórica, 114-119.

${ }^{44}$ Para el empleo de este refrán en la poesía del siglo XV, véase el índice de refranes incluido por Dutton, El cancionero del siglo XV, VII. Quizás haya que considerar además que el refrán se utilizó en el siglo XVI en la traducción de Bernardino Daza Pinciano de los emblemas de Alciato: el lema Cum larvis non luctandum ('no se ha de luchar con los muertos'), que se refiere al tema de la muerte y figuraba ya en la edición latina de 1531 (Alciato, Eblemas, 195), es traducido por Daza Pinciano en 1549 con el refrán "a moro muerto gran lanzada" (Alciato, Los emblemas de Alciato, 80); importa subrayar la fecha porque quizá la composición de nuestro texto se haga por esas fechas (el refrán, bien conocido desde tiempo antes, habría cobrado vigencia merced a la traducción castellana de Alciato).
} 
siempre voy empeorando", "que, quanto cruel me ha sido, / me sea tan piadosa"), la paradoja ("Muerto me puedo llamar / pues bivo siempre penando")... En suma, nuestra pieza, aunque sin duda compuesta en la primera mitad del Quinientos, se inscribe como otras muchas producciones del momento en la estela poética del siglo anterior.

Textualmente la prueba de pluma que nos ocupa solo incluye la primera estrofa del poema, que presenta algunas variantes con respecto a la versión ofrecida por el pliego impreso hacia 1558, en donde, tras el título, se leen los versos de la columna de la izquierda: ${ }^{45}$

Muy desseada señora: Muy deseada señora:

de mí, que soy su criado, de mí, que soy su criado, como mi mal empeora, como mi mal enpeora, la quise hazer sabidora la quise hacer sabidora

5 por lo que verá trobado. por lo que verá trovado. De donde podrá entender, Por ende puede entender, mi reyna, quánto al presente señora, quánto al presente -y puédelo bien creer-sy puédelo bien crerque holgara más de ser que quisiera yo más ser

10 mensajero que escribiente. mensagero que escribiente

Siquiera para gozar, Siquiera para señora, de ver su gesto, que tiene tan sigular, qual no se podría hallar

15 en el mundo más dispuesto. Porque soys tan acabada y hecha por tal perfeción, de mil virtudes dotada,

${ }^{45} \mathrm{Me}$ limito a introducir puntuación y acentos. Transcribo la segunda estrofa completa, aunque en la prueba de escritura no se acaba de copiar el primer verso. 
que mi pluma está cansada,

20 buscando comparación. ${ }^{46}$

Por lo que respecta a las diferencias entre una y otra versión, nada hay de extraño en ello: quien lleva a cabo la prueba de pluma muy posiblemente recupera de su memoria una pieza conocida; esto es, no copia de un modelo escrito que tiene ante los ojos.

Por más que no sean muchas las noticias sobre este autor, quizás este texto, del que hasta la fecha conocíamos solo la versión del pliego suelto, tuvo más éxito del que tan reducido número de testimonios conservados nos permite suponer. Tenemos aquí, pues, una nueva muestra del interés de las intervenciones ocasionales que a menudo distintas manos con diferentes propósitos (llevar a cabo una lectura anotada, ensayar la pluma, una mera distracción...) introducen en los espacios en blanco de códices e impresos.

\section{REFERENCIAS}

Alciato, Andrea, Emblemas, ed. Santiago Sebastián, Madrid, Akal, 1985.

Alciato, Andrea, Los emblemas de Alciato: traducidos en rimas españolas [1549], ed. facs. Rafael Zafra, Barcelona, José J. Olañeta y Universitat de les Illes Balears, 2003.

BARrio Moya, José Luis, “José Martín de Aldehuela y su intervención en la Iglesia de la Concepción Francisca en Cuenca", Teruel, 86: 2, 1998, 63-86.

${ }^{46}$ Aun cuando la brevedad de la probatio pennae no permite que se transparente la mezcla de formas de tercera persona ("su criado", "la quise hazer sabidora") y de segunda ("soys tan acabada", "causó en vos no ser humano / vuestro gesto angelical") para dirigirse a la destinataria de la carta (en ambos casos como formas de tratamiento deferenciales), esa mezcla se percibe con claridad en el testimonio del pliego suelto. 
Bibliotecas antigua y nueva de escritores aragoneses de Latassa por don Miguel Gómez Uriel, ed. electrónica a cargo de José Pedraza Gracia, José Ángel Sánchez Ibáñez y Luis Julve Larraz, Zaragoza, Prensas Universitarias de Zaragoza, 2001.

Cañas Murillo, Jesús y Miguel Ángel Teijeiro Fuentes (eds.), $\mathrm{Ca}$ tálogo bibliográfico de escritores extremeños anteriores a 1750, Badajoz, Diputación de Badajoz-Junta de Extremadura, 4 vols., 2010.

Casas Rigall, Juan, Agudeza y retórica en la poesía amorosa de cancionero, Santiago de Compostela, Universidad de Santiago, 1995.

Castañeda, Vicente y Amalio Huarte (eds.), Nueva colección de pliegos sueltos, Madrid, Tipografía de Archivos, 1933.

Chas Aguión, Antonio, "Los testamentos en la poesía de cancionero", Revista de Poética Medieval, 16, 2006, 53-78.

Corominas, Juan y José Antonio Pascual, Diccionario crítico etimológico castellano e hispánico, Madrid, Gredos, 6 vols., 19801991.

Covarrubias Horozco, Sebastián de [1611], Tesoro de la lengua castellana o española, Ignacio Arellano y Rafael Zafra (eds.), Madrid-Frankfurt, Iberoamericana-Vervuert, 2006.

Cuesta Gutiérrez, Luisa, La imprenta en Salamanca: avance al estudio de la tipografia salmantina (1480-1944), Salamanca, Universidad de Salamanca, 1960.

Delgado Casado, Juan, Diccionario de impresores españoles (siglos XVI-XVII), Madrid, Arco/Libros, 2 vols., 1996.

Díez Fernández, J. Ignacio, "Notas sobre la carta en octosílabo", en La epistola: V Encuentro Internacional sobre Poesía del Siglo de Oro, Begoña López Bueno (dir.), Madrid, Universidad Complutense, 2000, 151-180.

Di Stefano, Giuseppe, "Aggiunte e postille al Diccionario de pliegos sueltos poéticos di A. Rodríguez-Moñino”, Studi Mediolatini e Volgari, XX, 1972, 141-168.

Durán, Agustín, "Catálogo por orden alfabético de varios pliegos sueltos impresos en el siglo XVI", en Romancero general o colección de romances castellanos anteriores al siglo XVIII, I, Madrid, Rivadeneyra, 1849, LVII-LXXX. 
Dutton, Brian, con Jineen Krogstad, El cancionero del siglo XV (ca. 1360-1520), Salamanca, Biblioteca Española del Siglo Xv-Universidad de Salamanca, 7 vols, 1990-1991.

Fernández Valladares, Mercedes, La imprenta en Burgos (15011600), 2 vols., Madrid, Arco/Libros, 2005.

Gallardo, Bartolomé José, Ensayo de una biblioteca española de libros raros y curiosos [1863-1889], Madrid, Rivadeneyra, 4 vols. [ed. facs., Madrid, Gredos, 1968].

Gauthier, M. [Raymond Foulché-Delbosch], "De quelques jeux d'esprit", Revue Hispanique, XXXIII, 1915, 385-445.

Gómez-Bravo, Ana María, Repertorio métrico de la poesía cancioneril del siglo $\mathrm{XV}$, Alcalá de Henares, Universidad de Alcalá de Henares, 1998.

GonzÁlez Aranda, Yolanda, "El léxico toponímico en el Tesoro de Covarrubias", en Estudios de Historiografía Lingüistica. Actas del III Congreso Internacional de la Sociedad Española de Historiografia Lingüistica (Vigo, 7-10 de febrero de 2001), II, Miguel Ángel Esparza Torres, Benigno Fernández Salgado y Hans-Josef Niederehe (eds.), Hamburg, Helmut Buske, 2001, 861-876.

Labrador Herraiz, José J. y Ralph A. DiFranco, Tabla de los principios de la poesía española: Siglos XVI-XVII, Cleveland, Cleveland State University, 1993.

LANG, Henry R., "Las formas estróficas y términos métricos del Cancionero de Baena", en Estudios eruditos in memoriam Alfonso Bonilla y San Martín, Madrid, Viuda e Hijos de J. Ratés, I, 1927, 485-523.

LAPESA, Rafael, “'Cartas' y 'dezires' o 'lamentaciones' de amor: desde Santillana y Mena hasta don Diego Hurtado de Mendoza" [1989], en De Berceo a Jorge Guillén. Estudios literarios, Madrid, Gredos, 1997, 78-97.

Le Gentil, Pierre, La Poésie lyrique espagnole et portugaise à la fin du Moyen Âge, Rennes-Plihon, Féret et Fils, 2 vols., 1949-1953.

LóPEz Bueno, Begoña (dir.), La epistola: V Encuentro Internacional sobre Poesía del Siglo de Oro (Universidades de Sevilla y Córdoba, 23-26 de noviembre de 1998), Sevilla, Universidad de Sevilla, 2000. 
Mártir Rizo, Juan Pablo, Historia de la muy noble y leal ciudad de Cuenca [1629], Madrid, Herederos de la Viuda de P. de Madrigal, ed. facsímil, Barcelona, El Albir, 1974.

Moll, Jaime, "Tres volúmenes de pliegos sueltos de la biblioteca de Juan Nicolás Böhl de Faber", Boletín de la Real Academia Española, 48, 1968, 285-308.

Navarro Tomás, Tomás, Métrica española: reseña histórica y descriptiva, New York, Las Américas, 1966.

"Notas complementarias" a Miguel de Cervantes Saavedra, Don Quijote de la Mancha, volumen complementario, Francisco Rico (dir.), Barcelona, Instituto Cervantes-Crítica, 1998, 249-667.

Palau y Dulcet, Antonio, Manual del librero hispano-americano: bibliografía general española e hispano-americana desde la invención de la imprenta hasta nuestros tiempos con el valor comercial de los impresos descritos, Barcelona, Librería Anticuaria de A. Palau, 28 vols., 1948-1990.

Pérez Pascual, José Ignacio (ed.), La "Suma de la flor de cirugía" de Fernando de Córdoba, Noia, Toxosoutos, 2002.

Pérez Priego, Miguel Ángel (ed.), Marqués de Santillana, Poesía lírica, Madrid, Cátedra, 1999.

Periñán, Blanca, "Poeta ludens": Disparate, perqué y chiste en los siglos XVI y XVII, Pisa, Giardini, 1979.

Pliegos poéticos góticos de la Biblioteca Nacional, 6 vols., int. José Antonio García Nobleja, Madrid, Joyas Bibliográficas, 19571961.

Pontón, Gonzalo, Correspondencias: Los orígenes del arte epistolar en España, Madrid, Biblioteca Nueva, 2002.

Rodríguez-MoÑino, Antonio, Los poetas extremeños del siglo XVI: Estudios bibliográficos, Badajoz, Diputación Provincial, 1935.

Rodríguez-Moñino, Antonio, Manual bibliográfico de Cancioneros y Romanceros, III: Impresos durante el siglo XVII, I, Madrid, Castalia, 1977.

Rodríguez-MoÑIno, Antonio, Nuevo diccionario de pliegos sueltos poéticos (siglo XVI), ed. corregida y actualizada por Arthur L.-F. Askins y Víctor Infantes, Madrid, Castalia, 1997. 
Rosa, María del Carmen de la y María Ángeles Mosso, "Historia de las aguas mineromedicinales en España", Observatorio Medioambiental, 7, 2004, 117-137.

RuBio Árquez, Marcial, "Testamentos poéticos burlescos: hacia la definición de un subgénero literario popular", en La literatura popular impresa en España y en la América colonial. Formas \& temas, géneros, funciones, difusión, historia y teoría, Pedro M. Cátedra (dir.), y Eva Belén Carro Carbajal et al. (eds.), Salamanca, SEMYR-Instituto de Historia del Libro y de la Cultura, 2006, 241-251.

TAто, Cleofé, "Una nueva y fragmentaria versión del romance 'Muerto yaze Durandarte' en una probatio calami', Revista de Filología Española, XC: 2, 2010, 279-302.

Viudas Camarasa, Antonio, Diccionario extremeño, Cáceres, Universidad de Extremadura, 1980. 